as defined only at points where $z$ is differentiable. I should prefer not to add this condition but to define differentiable by the property that $z$ is differentiable at any point at which $d z / \Delta z \rightarrow 1$ as the arbitrary increments of all the independent variables tend to zero: this definition, which seems more natural than any other, was suggested to me many years ago by Prof. D. Rees.

Rugby College of Engineering Technology, Yours faithfully, Eastlands, Rugby

[I promised to provide a little space for this subject, but it cannot go on much longer. E.A.M.]

To the Editor, The Mathematical Gazette.

DeAR SIR,-As to the Note 3084 in the Gazette, I said in my article on Linear Algebraic Equations that the theorem in question was not new; and in a footnote I cited the paper on the Pi Theorem where I first proved it in 1957. This antedates the book of Richards (1959); and in 1956, when the article was written, I was totally unaware of the Russian treatise of Gantmacher.

University of Houston, Yours sincerely, Louis Brand

Cullen Boulevard, Houston 4, Texas

To the Editor of The Mathematical Gazette

Dear Sir, -

Alfred North Whitehead

I should appreciate information concerning letters by and about Whitehead, other documents, and recollections of him, for a biography which I am undertaking with the approval and encouragement of his son T. N. Whitehead. I shall be in the United Kingdom this summer to pursue leads. Please reply to Passenger Mail, Thomas Cook \& Sons, 45 Berkeley Street, London W. 1.

Professor of Philosophy

VICTOR LOWE

The Johns Hopkins University

Baltimore, Maryland, U.S.A.

\title{
PROFESSOR WATSON AND MR. HOPE-JONES
}

While The Mathematical Gazette for May was being printed, we heard with deep regret of the deaths of two of our most senior members, both Vice-Presidents of the Association, Dr. G. N. Watson, F.R.S., and Mr. W. Hope-Jones. We hope to pay tribute later to all that they did for us over many years. 